\title{
Sensory conduction in medial and lateral plantar
}

\section{nerves}

\author{
S N PONSFORD \\ From the Department of Clinical Neurophysiology, Walsgrave Hospital, Coventry, UK
}

SUMMARY A simple and reliable method of recording medial and lateral plantar nerve sensory action potentials is described. Potentials are recorded with surface electrodes at the ankle using surface electrodes stimulating orthodromically at the sole. The normal values obtained are higher in amplitude than those obtained by the method described by Guiloff and Sherratt and are detectable in older subjects aged over 80 years. The procedure is valuable in the diagnosis of early peripheral neuropathy, mononeuritis multiplex; tarsal tunnel syndrome and in differentiation between pre and post ganglionic L5 S1 lesions.

The value of medial plantar sensory action potential (SAP) recording in the diagnosis of peripheral neuropathy and investigation of root or individual nerve lesions involving the leg or foot was clearly established by Guiloff and Sherratt. ${ }^{1}$ However, their method of stimulating at the big toe and recording at the ankle gives potentials of relatively small amplitude (mean amplitude $2 \cdot 3 \mu \mathrm{v}$, range $0-8 \cdot 1$ ). Averaging response in older subjects may be time consuming. In their series of 69 normal subjects, medial plantar SAPs were absent in three of 16 subjects aged 60 years or over. Iyer $e t a l^{2}$ reported that stimulation of the medial and lateral plantar nerves on the sole proximal to the metatarsophalangeal joints and recording at the ankle or vice versa is a simple and reliable method. In 30 controls mean amplitudes of $16.5 \mu \mathrm{v}$, range $8 \cdot 0-37 \mu \mathrm{v}$ for medial plantar and $11.0 \mu \mathrm{v}$, range 5.0-35.0 for lateral plantar SAPs were obtained by orthodromic stimulation, antidromic stimulation resulting in a slightly larger lateral plantar SAPs of $14.8 \mu \mathrm{v}$, range $8 \cdot 0-32 \cdot 0$. The age range of their controls was 15-49 years. The present study was carried out to extend the age range of controls and the range of clinical conditions examined by this method.

\section{Method}

Subjects lay prone or supine, their feet supported on pillows. The skin was cleaned with alcohol. Medial plantar stimulation was performed using a Medelec stimulator type

Address for reprint requests: S N Ponsford, Department of Clinical Neurophysiology, Walsgrave Hospital, Coventry CV2 2DX, UK.

Received 24 May 1987.

Accepted 14 August 1987
EL53051 applied to the sole just lateral to the first metatarsal, the anode level with metatarsophalangeal joint, the cathode thus overlying the first common digital nerve subserving contiguous surfaces of the great and second toes. For the lateral plantar, the stimulator was placed between the fourth and fifth metatarsals, the anode again level with the metatarsophalangeal joint, overlying the fourth common digital nerve supplying contiguous surfaces of the fourth and fifth toes. The stimulus consisted of a supramaximal square wave pulse of $0.1 \mathrm{~ms}$ duration delivered at $1 / \mathrm{s}$. Medelec recording electrodes SE20 53056 were placed posteriote to the medial malleolus, using the posterior tibial artery as landmark. The earth electrode was placed over the dorsum of the foot. Recordings were made using a Medelec MS6 or a Mystro electromyograph. Gain was set at $10 \mu \mathrm{v} / \mathrm{cm}$ with sweep duration of $5 \mathrm{~ms}$ and high frequency cut at $3 \cdot 2 \mathrm{KHz}$. Four or eight responses were averaged, increasing to 16 if responses were small.

Ambient temperature was $22-27^{\circ} \mathrm{C}$. Skin temperature was measured at the medial malleolus and sole and kept at $30-32^{\circ} \mathrm{C}$. The effects of reducing temperature on SAP latency and of stimulating at different sites along the medial plantar nerve with a fixed recording site were examined. Orthodromic stimulation was used because antidromic stimulation usually evoked a motor response obscuring the plantar SAP.

\section{Controls}

Thirty nine female and 20 male healthy volunteers were examined, ages ranging from 14 to 85 years. Individuals with a previous history of hip replacement, lumbar laminectomy, ankle or foot trauma, flat feet, peripheral neuropathy or diabetes mellitus were excluded.

\section{Patients}

Plantar SAPs were recorded, with other nerve conduction and EMG studies, in 24 patients: 10 with generalised symmetrical polyneuropathy of mild or moderate degree; one 
with motor neuronopathy with distal sensory symptoms; five with multiple mononeuropathy; two with preganglionic lumbosacral root lesions; three with postganglionic lumbosacral plexus lesions; one with tarsal tunnel syndrome; two with flat feet.

\section{Results}

\section{Control subjects}

Values for amplitude, latency and sensory conduction velocity for medial and lateral plantar SAPs are shown in tables 1 and 2 respectively. Medial plantar SAPs were readily obtained in all control subjects including those aged over 80 years. Lateral plantar SAPs were present in all subjects below the age of 60 but absent in the majority above this age. The effect of age on mean amplitude is shown in fig 1 . No correlation between age and sensory conduction velocity (SCV) was found. Comparison by Student's $t$ test of the amplitude of response in the medial and lateral plantar nerves on each side in 13 pairs where interelectrode distance was the same, showed no significant difference ( $90 \%$ confidence limits).

The effect of lowering the skin temperature on latency of the medial plantar SAP is shown in fig 2 . Stimulation at different sites along the medial plantar nerve approaching the fixed recording site at the

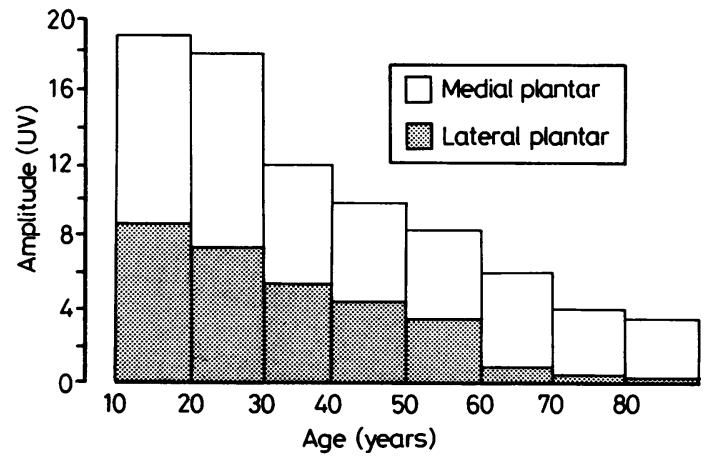

Fig 1 Relation between mean medial plantar/lateral plantar sensory action potential amplitude and age.

ankle is shown in fig 3 . The results in figs 2 and 3 demonstrate that the recorded potential is a true SAP.

\section{Patients}

Individual diagnoses and neurophysiological findings are shown in table 3.

\section{Discussion}

The results in control subjects confirm that the

Table 1 Medial plantar sensory action potential

\begin{tabular}{|c|c|c|c|c|c|c|c|c|c|c|c|c|c|}
\hline \multirow[b]{2}{*}{$\operatorname{Age}(y r)$} & \multirow{2}{*}{$\begin{array}{l}\text { Number } \\
\text { of } \\
\text { nerves }\end{array}$} & \multicolumn{3}{|c|}{ Amplitude $(\mu v)$} & \multicolumn{3}{|c|}{ Latency to onset ( $\mathrm{ms}$ ) } & \multicolumn{3}{|c|}{ Latency to peak (ms) } & \multicolumn{3}{|c|}{$\operatorname{Max} S C V(m / s)$} \\
\hline & & Mean & $S D$ & Range & Mean & $S D$ & Range & Mean & $S D$ & Range & Mean & $S D$ & Range \\
\hline $\begin{array}{l}10-19 \\
20-29 \\
30-39 \\
40-49 \\
50-59 \\
60-69 \\
70-79 \\
\geqslant 80 \\
\text { Total }\end{array}$ & $\begin{array}{r}14 \\
13 \\
16 \\
18 \\
11 \\
11 \\
10 \\
7 \\
100\end{array}$ & $\begin{array}{r}18 \cdot 78 \\
17 \cdot 85 \\
11.75 \\
9 \cdot 55 \\
8 \cdot 18 \\
6.01 \\
3.74 \\
3.64 \\
9.94\end{array}$ & $\begin{array}{l}4 \cdot 57 \\
7 \cdot 22 \\
3 \cdot 73 \\
4 \cdot 37 \\
3 \cdot 43 \\
1 \cdot 46 \\
1 \cdot 51 \\
1 \cdot 70 \\
3 \cdot 50\end{array}$ & $\begin{array}{c}10-26 \\
10-30 \\
7-20 \\
5-20 \\
3-15 \\
4 \cdot 0-8 \cdot 0 \\
2 \cdot 0-5 \cdot 0 \\
2 \cdot 0-7 \cdot 0 \\
2 \cdot 0-30\end{array}$ & $\begin{array}{l}2 \cdot 71 \\
2 \cdot 46 \\
2 \cdot 51 \\
2 \cdot 67 \\
2 \cdot 88 \\
2 \cdot 76 \\
3 \cdot 29 \\
3 \cdot 73 \\
2 \cdot 88\end{array}$ & $\begin{array}{l}0.33 \\
0.17 \\
0.23 \\
0.53 \\
0.69 \\
0.33 \\
1.07 \\
0.88 \\
0.53\end{array}$ & $\begin{array}{l}2 \cdot 0-3 \cdot 2 \\
2 \cdot 1-2 \cdot 7 \\
3 \cdot 0-2 \cdot 9 \\
2 \cdot 2-4 \cdot 4 \\
2 \cdot 2-4 \cdot 4 \\
2 \cdot 2-3 \cdot 2 \\
2 \cdot 0-4 \cdot 9 \\
2 \cdot 9-5 \cdot 6 \\
2 \cdot 0-5 \cdot 6\end{array}$ & $\begin{array}{l}3 \cdot 29 \\
3 \cdot 12 \\
3 \cdot 16 \\
3 \cdot 36 \\
3 \cdot 62 \\
3 \cdot 39 \\
4 \cdot 23 \\
4 \cdot 80 \\
3 \cdot 62\end{array}$ & $\begin{array}{l}0.32 \\
0.24 \\
0.36 \\
0.64 \\
0.88 \\
0.40 \\
1.39 \\
1.08 \\
0.66\end{array}$ & $\begin{array}{l}2 \cdot 5-3 \cdot 7 \\
2 \cdot 7-3 \cdot 4 \\
2 \cdot 8-3 \cdot 9 \\
2 \cdot 6-5 \cdot 5 \\
2 \cdot 8-5 \cdot 2 \\
2 \cdot 8-3 \cdot 9 \\
2 \cdot 5-6 \cdot 0 \\
3 \cdot 8-7 \cdot 0 \\
2 \cdot 5-7 \cdot 0\end{array}$ & $\begin{array}{l}49 \cdot 43 \\
54 \cdot 23 \\
54 \cdot 12 \\
52 \cdot 16 \\
52 \cdot 27 \\
48 \cdot 73 \\
49 \cdot 40 \\
40 \cdot 57 \\
50 \cdot 11\end{array}$ & $\begin{array}{r}4 \cdot 79 \\
4 \cdot 36 \\
4 \cdot 11 \\
5 \cdot 10 \\
3.47 \\
5.68 \\
13 \cdot 21 \\
5 \cdot 76 \\
5 \cdot 81\end{array}$ & $\begin{array}{l}41-57 \\
50-62 \\
50-64 \\
45-61 \\
48-60 \\
41-59 \\
33-65 \\
30-47 \\
30-65\end{array}$ \\
\hline
\end{tabular}

Table 2 Lateral plantar sensory action potential

\begin{tabular}{|c|c|c|c|c|c|c|c|c|c|c|c|c|c|}
\hline \multirow[b]{2}{*}{ Age (yr) } & \multirow{2}{*}{$\begin{array}{l}\text { Number } \\
\text { of } \\
\text { nerves }\end{array}$} & \multicolumn{3}{|c|}{ Amplitude ( $\mu v)$} & \multicolumn{3}{|c|}{ Latency to onset ( $\mathrm{ms}$ ) } & \multicolumn{3}{|c|}{ Latency to peak ( $\mathrm{ms}$ ) } & \multicolumn{3}{|c|}{$\operatorname{Max} S C V(m / s)$} \\
\hline & & Mean & $S D$ & Range & Mean & $S D$ & Range & Mean & $S D$ & Range & Mean & $S D$ & Range \\
\hline $10-19$ & 14 & $8 \cdot 71$ & 3.91 & $4 \cdot 0-16$ & $2 \cdot 79$ & 0.39 & $1 \cdot 9-3 \cdot 3$ & $3 \cdot 35$ & 0.40 & $2 \cdot 4-3 \cdot 7$ & $49 \cdot 78$ & $6 \cdot 21$ & $38-63$ \\
\hline $20-29$ & 13 & $7 \cdot 53$ & $2 \cdot 00$ & $5 \cdot 0-12$ & $2 \cdot 52$ & 0.12 & $2 \cdot 3-2 \cdot 7$ & $3 \cdot 21$ & $0 \cdot 23$ & $2 \cdot 8-3 \cdot 5$ & 53.85 & 3.78 & $50-62$ \\
\hline $30-39$ & 16 & $5 \cdot 56$ & $2 \cdot 50$ & $2 \cdot 0-10$ & $2 \cdot 63$ & 0.27 & $2 \cdot 3-3 \cdot 1$ & $3 \cdot 29$ & 0.36 & $2 \cdot 9-3 \cdot 9$ & $54 \cdot 18$ & $4 \cdot 18$ & $50-64$ \\
\hline $40-49$ & 14 & $4 \cdot 32$ & $1 \cdot 17$ & $3 \cdot 0-6 \cdot 0$ & $2 \cdot 72$ & 0.44 & $2 \cdot 3-3 \cdot 1$ & 3.46 & 0.56 & $2 \cdot 8-5 \cdot 0$ & $51 \cdot 57$ & 6.09 & $40-61$ \\
\hline $50-59$ & 10 & $3 \cdot 79$ & $1 \cdot 71$ & $1 \cdot 0-6 \cdot 0$ & $2 \cdot 97$ & 0.78 & $2 \cdot 2-5 \cdot 0$ & $3 \cdot 72$ & 0.92 & $3 \cdot 2-6 \cdot 3$ & $51 \cdot 30$ & $2 \cdot 87$ & $45-56$ \\
\hline $60-69$ & $11^{*}$ & 1.0 & 1.48 & $0-4.0$ & 3.05 & 0.75 & $0-4 \cdot 0$ & $3 \cdot 73$ & 0.81 & $0-4 \cdot 8$ & $47 \cdot 25$ & $7 \cdot 80$ & $0-54$ \\
\hline $70-79$ & $10+$ & 0.55 & 0.76 & $0-2.0$ & 3.93 & 1.93 & $0-5.6$ & $4 \cdot 73$ & $2 \cdot 17$ & $0-6.7$ & $47 \cdot 50$ & $13 \cdot 28$ & $0-59$ \\
\hline$\geqslant 80$ & $7+$ & 0.14 & 0.38 & $0-1.0$ & - & - & - & - & - & - & -- & - & \\
\hline Total & $95^{+}$ & 3.94 & $1 \cdot 74$ & $0-16$ & 2.94 & 0.67 & $0-5.6$ & $3 \cdot 64$ & 0.78 & $0-6.7$ & $50 \cdot 78$ & $6 \cdot 32$ & $0-64$ \\
\hline
\end{tabular}

* Lateral plantar SAP was absent in seven out of 11 controls.

†Lateral plantar SAP was absent in six out of 10 controls. (Mean values etc., for latency and MCV were calculated from the remaining cases.)

+Lateral plantar SAP was absent in seven out of eight controls. The amplitude in the remaining case was $1 \mu \mathrm{v}$, latency to onset was $2.9 \mathrm{~ms}$, latency to peak was $3.6 \mathrm{~ms}$, and conduction velocity was $52 \mathrm{~m} / \mathrm{s}$. 
Table 3 Medial plantar and other sensory action potentials in 24 patients

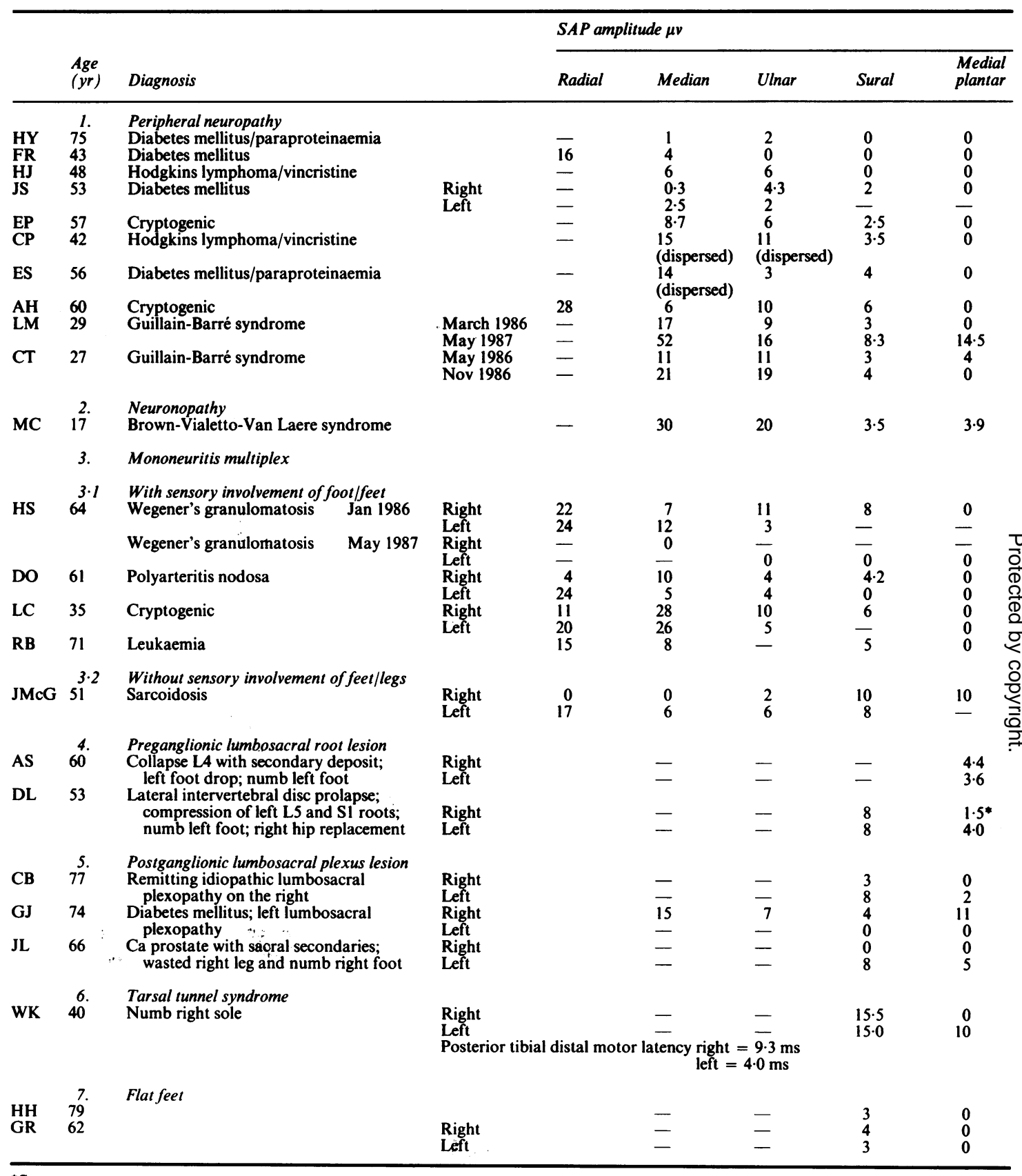

*See text.

present technique of stimulating the sole (rather than the big toe) provides a simple, reliable method of measuring the plantar SAP. Medial plantar SAPs were found consistently in all controls including four subjects in their ninth decade (oldest 85). Mean amplitude in the present study for subjects 10-49 years was $14.0 \mu \mathrm{v}$ (range 5-30) which is consistent with that found by Iyer et al, while mean amplitudes for each decade examined were consistently larger than those found by Guiloff and Sherratt. The larger 


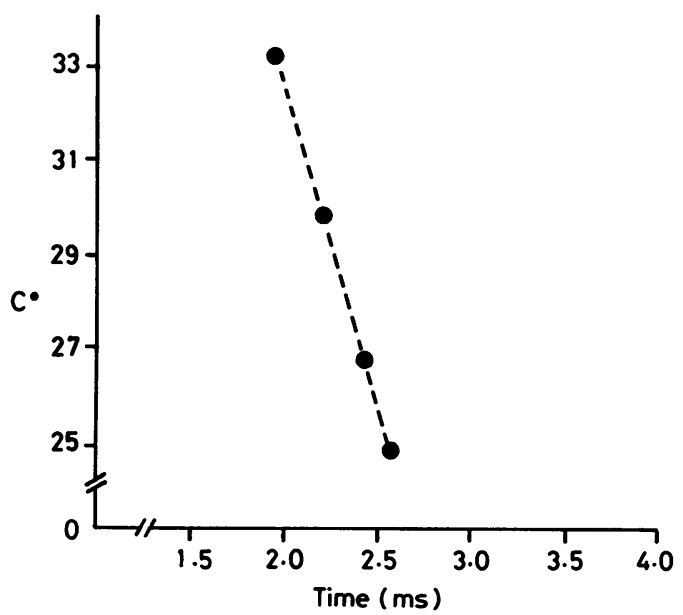

Fig 2 Effect of temperature on latency of medial plantar $S A P$.

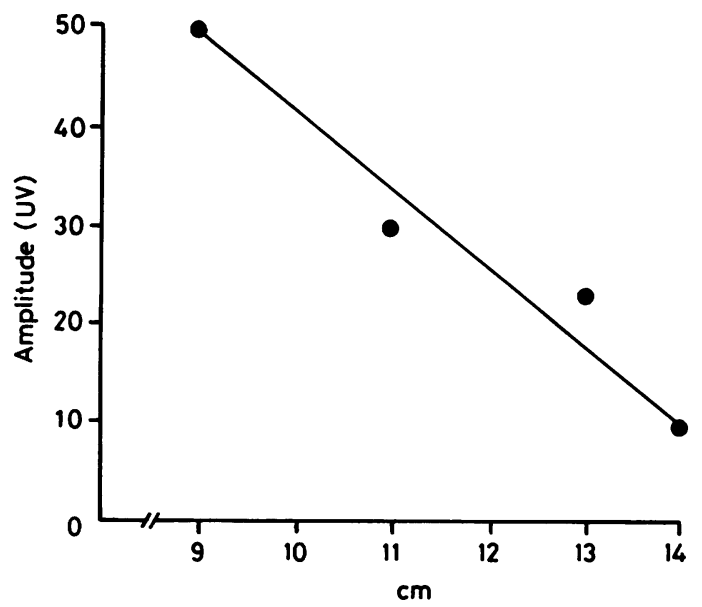

Fig 3 Effect of site of stimulation on amplitude of medial plantar SAP.

responses in the present series undoubtedly help to account for the relative preservation of responses in older subjects and presumably reflect a larger number of axons at the point of stimulation. As with Guiloff and Sherratt, the regression of the mean amplitude with age is striking, suggesting that the range of control values for each decade be taken into account when interpreting results in practice. Indeed, the regression with age in lateral plantar SAP is such that responses were absent in the majority of subjects in the seventh decade or above.

The results in patients strongly support the conclusion of Guiloff and Sherratt that the medial plantar SAP is a more sensitive diagnostic test than sural and median SAPs in peripheral neuropathy. Medial plantar SAPs were consistently absent in such patients with detectable, if reduced, sural SAPs, whilst median SAPs were frequently within the normal range. Plantar SAPs were similarly of value in patients with mononeuritis multiplex in which sensory symptoms were outside sural nerve territory. The specificity of the test in relation to symptoms is perhaps further illustrated in the patient JMcG with multiple mononeuritic symptoms and signs involving the right arm with clinical and electrical sparing of the feet.

Comparison of preganglionic lumbosacral root and postganglionic lumbosacral plexus lesions associated with sensory loss in the medial plantar territory shows the expected preservation and loss of SAP respectively. In all the present cases symptoms had been present for over a month: caution would be necessary in interpreting results in such lesions of very recent onset.

In the patient DL with left sided lumbar root pain, numbness of the left foot and left sided lumbar disc prolapse, a medial plantar SAP was found within the normal range at $4 \mu \mathrm{v}$ on the left with a small SAP of $1.5 \mu \mathrm{v}$ on the right. The small right sided SAP may be related to sciatic nerve disturbance at the time of hip replacement. The patient had complained of vague numbness in the right leg and foot ever since the operation.

The effect of flat feet was examined in two otherwise asymptomatic volunteers. Medial and lateral plantar SAPs were absent in both. If not a developmental abnormality of the nerve, it seems likely that this was due to a chronic pressure effect. Hence caution is required in interpretation of results in this condition. Apart from this caveat, and with due attention to foot skin temperature, it is concluded that recording the medial plantar SAP using surface electrodes stimulating the common digital nerve and recording at the ankle merits routine if not first line use in patients with peripheral neuropathy and provides a reliable complement to the sural SAP in the diagnosis or exclusion of postganglionic lesion involving the lower limb.

I thank the physicians and neurologists of Walsgrave Hospital who allowed their patients to be in this study, the control subjects who volunteered, Drs $\mathbf{R}$ Paul and JR Ponsford for encouragement and advice and Mrs AV Harding for typing the manuscript.

\section{References}

1 Guiloff RJ, Sherratt RM. Sensory conduction in medial plantar nerve. $J$ Neurol Neurosurg Psychiatry 1975;40:1168-81.

2 Iyer KS, Kaplan E, Goodgold J. Sensory action potentials of the medial and lateral plantar nerve. Arch Phys Med Rehab 1984;65:529-60. 